\title{
An Indicator to Evaluate the Environmental Impact of Olive Oil Waste Water's Shedding on Cultivated Fields
}

\author{
Nicola Silvestri*, Gianni Fila ${ }^{2}$, Gianni Bellocchi² ${ }^{2}$ Enrico Bonari ${ }^{3}$ \\ ${ }^{1}$ Dipartimento di Agronomia e Gestione dell'Agroecosistema \\ Via San Michele degli Scalzi 2, 56124 Pisa, Italy \\ ${ }^{2}$ Istituto Sperimentale per le Colture Industriali, Bologna, Italy \\ ${ }^{3}$ Scuola Superiore di Studi Universitari e Perfezionamento Sant'Anna, Pisa, Italy
}

Received: 8 October 2003. Accepted: 10 March 2006

\begin{abstract}
Several climatic, soil and topographic factors need to be considered when evaluating the impact of human actions on the environment. Such variables may be related in a complex way to environmental impact, thus making its evaluation difficult. Problems of this type emerge when evaluating the risks olive oil waste water pose to the environment when shed on cultivated soils. This paper proposes a fuzzy expert system to calculate a modular indicator, ICARO, which allows an evaluation of the potential environmental impact of the application of olive oil waste water in a field. Five modules were formulated, one ("Waste water") reflecting the nature of the waste water, two ("Groundwater", "Surface water") reflecting the risk for the most sensitive agro-environmental compartments (groundwater, surface water), one ("Crop") reflecting possible consequences on the cropping system adopted, and one ("Soil") reflecting the soil aptitude to receive waste waters. The input variables are therefore waste water amount and properties, site-specific conditions, and characteristics of the application considered. For each input variable, two functions describing membership to the fuzzy subsets Favorable (F) and Unfavorable (U) have been defined. The expert system calculates the value of each module according to both the degree of membership of the input variables to the subsets $\mathrm{F}$ and $\mathrm{U}$, and a set of decision rules. The five modules can be considered individually or can be aggregated (again according to level of membership to fuzzy subsets $\mathrm{F}$ and $\mathrm{U}$ and a set of decision rules) into the synthetic indicator ICARO. Outcomes of a sensitivity analysis are presented. The system is flexible and can be used as a decision aid tool to authorize waste water's shedding or subordinate the distribution on fields to acceptance of some limitations (amount, timing, site, etc).
\end{abstract}

Key-words: environmental impact, expert system, fuzzy logic, ICARO, olive oil, waste water.

\section{Introduction}

Oil extraction from olive pulp is performed separating oil from the rest simply by pressure (traditional system) or, alternatively, by centrifugation (more modern system) using either a threephase or two-phase decanter system. The centrifugation two-phase decanter system is not a source of liquid waste (ordinarily said waste water) which, on the contrary, originates with both other technologies, although in different quantities (about 400-600 1 per ton of olives with the traditional system, about 800-1000 l per ton of olives with the centrifugation system with threephase decanter system, according to Di Gio- vacchino (2001). About $2 \times 10^{6}$ liters of waste water is produced yearly in Italy, and similar situations can be found in the other countries where olive oil is produced (Spain, Greece, northern Africa and Middle-East countries) (Rana et al., 2003).

The composition of the waste water emulsion could change very much in relation to climatic and soil conditions, agronomic management, cultivar choice, oil extraction method, etc. Nonetheless, olive oil waste waters are always potentially polluting and constitute a major source of organic pollution in the Mediterranean region, due to the high organic carbon 
content, substantial portion of which is present as aromatic compounds with known bio-toxicological activity (phenols, polyphenols and tannins), and the considerable values of acidity and salinity (Potenz et al., 1985; Zouari and Ellouz, 1996; Ciafardini et al., 1998; De Simone et al., 1998). Environmental problems take place, as large quantities of waste waters are produced during a short period of time.

Several chemical and biological technologies are increasingly used in order to transform olive oil waste water into more biodegradable residues, some with success, but they are insufficient to permit discharges of effluents into the environment, and not cost effective because of the seasonal character of production and the small size of extraction plants (Borja et al., 1992; Matzavinos et al., 1996; Benitez et al., 1997; Poulios et al., 1999; Coombs and Hall, 2000). Alternatively, shedding oil waste water on cultivated fields might be a suitable solution, if performed under controlled regimes (Bonari and Silvestri, 2003). However, waste waters shedding poses risks to environmental compartments like water and soil and the optimization of this practice is a serious need (Tomati, 2001).

The Italian legislation is based on the law $\mathrm{n}$. $574 / 96$, pertaining to norms concerning agricultural utilization of waters from olive oil industry. In particular, it establishes: 1) the maximum amount of oil waste waters that is possible to shed on fields, 2) the categories of suitable lands for the distribution, and 3) the norms for water storage. In general, the risk of phytotoxicity to the crop and the environmental cost are the main factors considered when proposing waste water's shedding on cultivated fields. In particular, the definition of the site-specific conditions for distribution (amount, modes, timing, and the most suitable equipments) according to agronomic, pedological, orographic and climatic characteristics is required, thus avoiding the onset of either undesired (e.g., limited drainage, smell emissions, etc.) or quite dangerous (e.g., groundwater pollution, superficial water bodies contamination, etc.) phenomena. Both farmers and public decision-makers would like to be able to take the potential environmental impact of the waste water's shedding into account.

Giving a solid judgment about the impact on the environment associated to waste water's shedding requires to simultaneously consider several variables. Balancing different aspects involved in the discourse is a complex process. Hence, combining several variables into one aggregated measure is desirable in order to have a comprehensive assessment of the environmental impact. This could be achieved by aggregating variables by summation, multiplication, or a combination of both. These approaches pose mathematical and conceptual problems (Keeney and Raiffa, 1993), since the relevant variables differ in their nature, dimensions and range of possible values. Considering the inadequacy of such methods, a different approach to evaluate the environmental impact can rely in setting up a fuzzy expert system (Hall and Kandel, 1991) using decision rules (fuzzification). This technique is robust on uncertain and imprecise data such as subjective judgments (Duboy and Prade, 1980; Bardossy et al., 1985; Goyal and Deshpande, 2001), and allows the aggregation of dissimilar variables in a consistent and reproducible way (Bouchon-Meunier, 1993).

Within the last decades methods of this type have been proposed for estimating the environmental impact of xenobiotic substances. Some methods assess potential xenobiotic environmental impact, as perceived by the "experts" that created them. We are not aware methods of this type exist for evaluating the impact on the environment of waste waters from olive oil industry when they are shed on cultivated fields. This paper describes an expert system which is at the core of an agro-ecological indicator, ICARO, reflecting an expert perception of the impact of waste water's shedding on the environment.

\section{Methods}

\subsection{Structure of the indicator and fuzzy expert reasoning}

It is assumed here that a comprehensive assessment about the impact of waste water's shedding on the environment should consider: i) the amount of waste water to be shed in a field and its composition, ii) the proneness to which the waste water can leave the field on which it is applied to reach groundwater and surface water, iii) the possible toxicity to crops, and iv) the effect on soil quality generated by the waste water interaction with soil properties. 
Such assumptions do conform to a general tenet (e.g., Bacci et al., 1989), by which procedures aimed at assessing the impact of a given action on the environment imply the identification of three key components, i.e. source, critical path, and target. The source is the point or non-point origin of the pollutant. The critical path is the array of mechanisms allowing the transfer and spread of pollutants to the target; criticality lies on the efficiency this process is played. The target is the last or intermediate environmental compartment receiving the impact.

In the problem of interest the source is given by the waste water to be shed in a field. The modes by which this potential pollutant spreads out in the environment are associated to deep drainage, surface runoff, crop absorption, and soil interactions. Such issues may include factors of energy, resistance, protection, and vulnerability. Energy factors foster impact transmission to target, resistance factors pose possible opposition to such a transmission, protection factors attenuate the effect of the impact on the target, and vulnerability factors generate potential conditions for major danger. The critical ways here recognized do indeed identify corresponding environmental targets: groundwater, surface water, crop, soil.

According to such premises, we defined five indicator modules, named "Waste water" ("Refluo" in Italian), "Groundwater" ("Falda" in Italian), "Surface water" ("Corpi idrici" in Italian), "Crop" ("Coltura" in Italian), "Soil" ("Suolo" in Italian). The value of each module depends on one or more input variables and a set of $2^{\mathrm{n}}$ decision rules, $\mathrm{n}$ being the number of inputs in a module. For each module, a dimensionless value between 0 (no risk of environmental impact) and 1 (maximum risk of environmental impact) is calculated. The procedure, based on the multi-valued fuzzy set theory introduced by Zadeh (1965), follows the so-called Sugeno or Takagi-Sugeno-Kang method of fuzzy inference (Sugeno, 1985).

It consists of four functional components: 1) a fuzzifier that transforms numerical inputs into fuzzy sets (fuzzification), 2) a set of control rules governing the relationships between inputs and outputs, 3) an inference engine that performs the fuzzy reasoning based on the control rules, and 4) a defuzzifier that transforms the fuzzy output into real numerical numbers (defuzzification).
This approach, computationally efficient and well-suited for mathematical analysis, has been applied to a wide variety of problems. Relevant applications were, for instance, the development of novel approaches to support decisions regarding sustainable development (Cornelissen et al., 2001), the estimation of parameters in evapotraspiration models (Odhiambo et al., 2001), and the evaluation of radiation model performance (Bellocchi et al., 2002). In the context of environmental impact, a fuzzy-based indicator was designed by van der Werf and Zimmer (1998) and enhanced by Roussel et al. (2000), reflecting an expert perception of the potential environmental impact of the application of a pesticide in a field crop. The approach followed here is largely inspired to such contributions, and the reader may refer to them for details on computational issues of the fuzzy inference process. We only report hereafter some basics of the fuzzy procedure we have followed.

Fuzzification was achieved by categorizing the input data space for each input variable into three membership classes (or subsets): Favorable (F), Unfavorable (U), and partial (or fuzzy) membership; the output data space was attributed a decision rule in the form of an expert weight. The control rules for estimating module values were based on rational relationships between inputs and outputs, expressed in linguistic terms by if-then statements. For example, when two input variables are aggregated, four rules are formalized as follows:

$\begin{array}{ll}\text { premise } & \text { conclusion } \\ \text { if } \mathrm{x}_{1} \text { is } \mathrm{F} \text { and } \mathrm{x}_{2} \text { is } \mathrm{F} & \text { then } \mathrm{y}_{1} \text { is } \mathrm{B}_{1} \\ \text { if } \mathrm{x}_{1} \text { is } \mathrm{F} \text { and } \mathrm{x}_{2} \text { is } \mathrm{U} & \text { then } \mathrm{y}_{2} \text { is } \mathrm{B}_{2} \\ \text { if } \mathrm{x}_{1} \text { is } \mathrm{U} \text { and } \mathrm{x}_{2} \text { is } \mathrm{F} & \text { then } \mathrm{y}_{3} \text { is } \mathrm{B}_{3} \\ \text { if } \mathrm{x}_{1} \text { is } \mathrm{U} \text { and } \mathrm{x}_{2} \text { is } \mathrm{U} & \text { then } \mathrm{y}_{4} \text { is } \mathrm{B}_{4}\end{array}$

where $x_{i}$ is an input variable, $y_{i}$ is an output variable and $\mathrm{B}_{\mathrm{i}}$ is a decision rule (or expert weight). A "minimum operator" was used to evaluate the conjunction and by taking the minimum of the quantified fuzzy sets, as obtained from complementary S-shaped distribution curves. Figure 1 shows S-shaped curves for an hypothetical input variables ranging from $1.0(\mathrm{~F})$ to $2.5(\mathrm{U})$. The S-function is flat at values of the input variables beyond $\mathrm{F}$ and $\mathrm{U}$.

The output fuzzy sets for all the rules were aggregated into a single fuzzy set. The aggregate output fuzzy set encompasses a range of output 


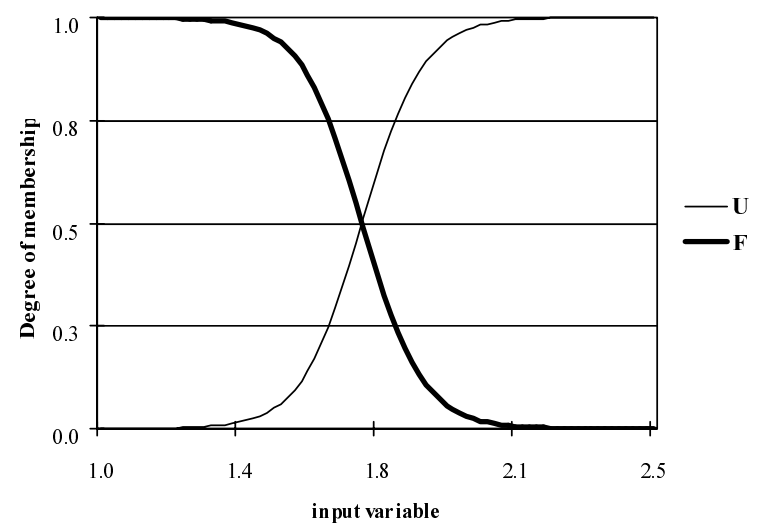

Figure 1. Graphical presentation of S-shaped curves for an hypothetical input variable.

values, and was defuzzified in order to resolve a single crisp output value from the set. The centroid method was selected to obtain the representative non-fuzzy value for the output, as commonly adopted in the Sugeno-type systems.

In this work several input variables were aggregated into modules, and the modules in the final indicator, using fuzzy-based logic rules. The expert reasoning runs as follows: if all input variables are $F$, the value of the module is 0 (no risk for the environment); if all indices are $\mathrm{U}$, the value of the module is 1 (maximum risk for the environment). In setting up the decision rules for the other combinations (some of the inputs are $\mathrm{F}$ while some others $\mathrm{U}$ ) we had to decide on the relative importance of each input, by attributing an expert weight to each of them. Computations are done by using weights which are normalized on a scale from 0 to 1 . A normalized weight $\left(b_{j}\right)$ is given by dividing its value by the sum of the weights of all variables to be aggregated. A decision rule is indeed the expert weight $\left(\mathrm{B}_{\mathrm{i}}\right)$ assigned to a given conjunction (... and ...) of inputs. The terms $\mathrm{B}_{\mathrm{i}}$ and $\mathrm{b}_{\mathrm{i}}$ are related as follows:

$$
B_{i}=1-\sum_{j^{F}=1}^{n^{F}} b_{j}^{F}
$$

where $\mathrm{i}$ is the $\mathrm{i}^{\text {th }}$ rule, $\mathrm{j}^{\mathrm{H}}$ is the $\mathrm{j}^{\text {th }}$ input variable which enters the decision rule as $\mathrm{F}, \mathrm{n}^{\mathrm{F}}$ is the number of input variables which enter the decision rule as $F, b_{j}^{F}$ is the normalized weight for one of the input variables which enter the decision rule as F. As an example, let's take three input variables and two hypothetical rules, e.g.: $\begin{array}{ll}\text { if } \mathrm{x}_{1}\left(\mathrm{~b}_{1}=0.40\right) \text { is } \mathrm{F} \text { and } \mathrm{x}_{2} & \text { then } \mathrm{y}_{1} \text { is } \mathrm{B}_{1}= \\ \left(\mathrm{b}_{2}=0.53\right) \text { is } \mathrm{F} \text { and } \mathrm{x} 3 & 1-(0.40+0.53) \\ \left(\mathrm{b}_{3}=0.07\right) \text { is } \mathrm{U} & =0.07\end{array}$

if $\mathrm{x}_{1}\left(\mathrm{~b}_{1}=0.40\right)$ is $\mathrm{U}$ and

$\mathrm{x}_{2}\left(\mathrm{~b}_{2}=0.53\right)$ is $\mathrm{U}$ and $\mathrm{x} 3$

$\left(b_{3}=0.07\right)$ is $F$

then $\mathrm{y}_{2}$ is $\mathrm{B}_{2}=$ $1-0.07=0.93$

When an input variable only enters the decision rule as $U$, the resulting value of $B_{i}$ is the relative incidence of such a variable into its own module. In the example above $B_{i}=0.07$ is the relative incidence of $\mathrm{x} 3$.

Both limits to the fuzzy subsets $\mathrm{F}$ and $\mathrm{U}$, and weights were, in general, established based on our expert judgment, working on data sets from multi-year researches carried out in different locations over the Region Tuscany (Bonari and Ceccarini, 1991, 1993, 2001, Bonari et al., 2001).

\subsection{The module "Waste water"}

The indicator module "Waste water" reflects quantity and quality of waste waters by means of the input variables listed in Table 1 . The $\mathrm{U}$ limits selected for the rate of application are those set by the Italian law 574/96, by which amounts higher than 80 and $50 \mathrm{~m}^{3} \mathrm{ha}^{-1}$, respectively for mechanical pressure and centrifugation methods, are forbidden. Other limits are extracted from Italian laws as well (legislative decree 152/99 for floating points; deliberation of the Committee of Ministers 04/02/1977 for SAR). Transition interval for $\mathrm{pH}$ tends to cover the range of values observed with olive oil waste waters (4.8 to 5.4 according to Fiorentini et al. (1985); 4.7 to 5.8 according to Pacifico (1989); other reference data are values fluctuating between 4.3 and 5.2, published in "Reflui e sottoprodotti della trasformazione delle olive", available through the web site of ARSIA-Toscana at http://www.arsia. toscana.it). Values limiting the transition interval for electric conductivity are derived by the permissible limits for classes of irrigation water given in James et al. (1982). In our experience, the quantity inputs assume more relevant importance than quality inputs in the environmental impact assessment, thus fairly large weights were attributed to rate of application and time from last shedding (10 and 6 , respectively).

Chemical composition was also considered in the short preliminary proposal of ICARO (Silvestri et al., 2003), including in the structure 
Table 1. The indicator module "Waste water": input variables, favorable (F) and unfavorable limits (U), expert weights. For details, see the text.

\begin{tabular}{|c|c|c|c|c|}
\hline \multicolumn{5}{|c|}{ Module "Waste water" } \\
\hline \multirow[t]{2}{*}{ Option } & \multirow[t]{2}{*}{ Input variable } & \multicolumn{2}{|c|}{ Limits } & \multirow[t]{2}{*}{ Expert weigh } \\
\hline & & $\mathrm{F}$ & $\mathrm{U}$ & \\
\hline \multicolumn{5}{|l|}{ quantity } \\
\hline centrifugation method & rate of application $\left(\mathrm{m}^{3} \mathrm{ha}^{-1}\right)$ & 16 & 80 & 10 \\
\hline mechanical pressure method & rate of application $\left(\mathrm{m}^{3} \mathrm{ha}^{-1}\right)$ & 10 & 50 & 10 \\
\hline- & time past from the last shedding (years) & 5 & 2 & 6 \\
\hline \multicolumn{5}{|l|}{ quality } \\
\hline- & floating impurities $\left(\mathrm{mg} \mathrm{l}^{-1}\right)$ & 80 & 200 & 1 \\
\hline- & $\mathrm{pH}(-)$ & 5.5 & 4.5 & 1 \\
\hline- & SAR (-) & 10 & 15 & 2 \\
\hline- & electric conductivity $\left(\mu \mathrm{S} \mathrm{cm}^{-1}\right)$ & 750 & 2000 & 2 \\
\hline
\end{tabular}

of the module "Waste water" the concentration of heavy metals such as manganese, zinc and copper present in the waste water. Following that, more in-depth studies led us through the decision to simplify this module by no longer taking metals into account, based on scientific, technical and legislative assessments. Three main issues underpin the core scientific ground. First, the three metals mentioned, although more frequently observed than others, correspond to a restricted sub-set of a larger assortment of metals at times detected in olive oil waste water, possibly including lead, nickel, cobalt, etc. Second, the combined effect of environmental factors and multiple sources of contamination (including crop management) is to generate complex and changing patterns in the allocation of metal impurities to waste waters; as a result, a strong seasonal variability of metal concentrations has been evidenced in waste waters of apparently similar origin (Di Giovacchino, 2001). Third, different combinations of metals could have different implications on various environmental compartments, therefore complex coefficient schemes should be considered where each combination of metals has its own weight. However, determining a set of coefficients that assess the joint effect of two or more metals on one or more environmental targets is not a trivial task, and never agreeably solved (e.g., Kuncheva et al., 2000). On a technical level, it must be considered that concentration values for metals in olive oil waste water are rarely available, as metal determination is not part of a standard laboratory analysis, and is often not done owing budgetary constraints (this would generate missing inputs to the indicator). Moreover, the law 574/96 does not say anything about metals, and typical values of metal concentration in olive oil waste waters are seldom compatible with the tolerance limits portrayed by non-specific reference legislation (e.g., legislative decree 152/99, defining general policy for water protection from pollution and processing of urban waste waters; deliberation of the Committee of Ministers 27/07/1984, pertaining to strategies for waste products disposal).

\subsection{The module "Groundwater"}

The indicator module "Groundwater" reflects the potential of waste waters to reach groundwater through leaching and to affect its potential use as a source of drinking water for humans. The value of "Groundwater" depends on three input variables: 1) soil saturation rate (energy), 2) saturation conductivity (resistance), 3) the field distance from wells (vulnerability). Table 2 re-

Table 2. The indicator module "Groundwater": input variables, favorable (F) and unfavorable limits (U), expert weights. For details, see the text.

\begin{tabular}{llrrr}
\hline \multicolumn{1}{c}{ Module "Groundwater" } & & \\
\hline Type of factor & Input variable & \multicolumn{2}{c}{ Limits } & Expert weight \\
\cline { 2 - 4 } & & $\mathrm{F}$ & $\mathrm{U}$ & \\
\hline energy & soil saturation rate $\left(\mathrm{d}^{-1}\right)$ & 0.25 & 0.75 & 6 \\
resistance & saturated hydraulic conductivity $\left(\mathrm{mm} \mathrm{h}^{-1}\right)$ & 0.36 & 36 & 8 \\
vulnerability & field distance from wells $(\mathrm{m})$ & 200 & 100 & 1 \\
\hline
\end{tabular}


Table 3. The indicator module "Surface water": input variables, favorable (F) and unfavorable limits (U), expert weights. For details, see the text.

\begin{tabular}{|c|c|c|c|c|}
\hline \multicolumn{5}{|c|}{ Module "Surface water" } \\
\hline \multirow[t]{2}{*}{ Type of factor } & \multirow[t]{2}{*}{ Input variable } & \multicolumn{2}{|c|}{ Limits } & \multirow[t]{2}{*}{ Expert weight } \\
\hline & & $\mathrm{F}$ & $\mathrm{U}$ & \\
\hline energy & rainfall erosivity $\left(\mathrm{MJ} \mathrm{mm} \mathrm{ha}^{-1} \mathrm{~h}^{-1} \mathrm{yr}^{-1}\right)$ & 1000 & 6000 & 4 \\
\hline energy & soil morphologic factor $(-)$ & 0.5 & 1.5 & 4 \\
\hline resistance & soil erodibility ( $\mathrm{t} \mathrm{h} \mathrm{MJ} \mathrm{Mm}^{-1}$ ) & 0.03 & 0.08 & 4 \\
\hline protection & cover factor $(-)$ & 0.2 & 1.0 & 8 \\
\hline vulnerability & conservation management (-) & 0 & 1 & 6 \\
\hline vulnerability & field distance from water bodies $(\mathrm{m})$ & 300 & 150 & 4 \\
\hline
\end{tabular}

ports the module features. Both membership limits and weights attributed to the input variables do conform to our expert judgment. Favorable and unfavorable boundaries for saturation conductivity do conform to the categorization proposed by the Soil Survey Staff and Natural Resource Conservation Service (1993). The saturated hydraulic conductivity, measuring the soil permeability, is closely related to potential groundwater contamination, and therefore this input was assigned the highest weight (i.e., 8). Soil saturation rate, expressed as a ratio between monthly rainfall and soil water holding, is also quite important (expert weight equal to 6).

\subsection{The module "Surface water"}

The indicator module "Surface water" reflects the potentials of waste waters to reach surface water through runoff or drift and to harm aquatic organisms. Its value depends on six input variables (Table 3): 1) the rainfall erosivity (energy), 2) a soil morphologic factor (energy), 3) the soil erodibility (resistance), 4) a cover factor (protection), 5) conservation management (protection), 6) field distance from water bodies (vulnerability).

With the only exception of field distance

Table 4. Cover factors of the module "Surface water".

\begin{tabular}{lc}
\hline Land use & Cover factor $(-)$ \\
\hline tilled fallow & 1.00 \\
untilled fallow & 0.50 \\
fallow with crop residues & 0.25 \\
tilled with weeds & 0.75 \\
cereals & 0.40 \\
mechanically weeded crops & 0.50 \\
rotated grasses & 0.10 \\
specialized olive trees & 0.60 \\
mix-cropped olive trees & 0.50 \\
straight row vineyards & 0.75 \\
contoured vineyards & 0.60 \\
permanent grasses & 0.01 \\
\hline
\end{tabular}

from water bodies, other inputs are based on the USLE (Universal Soil Loss Equation) approach (Wischmeier and Smith, 1978). Both limits and weights attributed to either input variables reflect the authors' experience. In general, crop management (ground cover, tillage, etc.) is assumed as the main factor governing the risk to surface water (expert weights equal to 8 and 6 to cover factor and conservation management, respectively). Both cover factor and conservation management are coefficients on a range from 0 (best) to 1 (worst). Cover factor accounts for land use (presence/absence of ground cover, type of crop/crop residues), as in Table 4 .

Conservation management accounts for possible farmer operations (i.e., tillage, buffers strips) which help protect surface water from waste waters (Table 5). When possible, tillage

Table 5. Conservation management coefficients of the module "Surface water".

\begin{tabular}{|c|c|c|c|}
\hline \multicolumn{2}{|c|}{ Management } & \multirow{2}{*}{$\begin{array}{c}\text { Slope } \\
(\%)\end{array}$} & \multirow{2}{*}{$\begin{array}{c}\text { Coefficien } \\
(-)\end{array}$} \\
\hline Buffer strips & Land treatment & & \\
\hline & - & 0 & 1.00 \\
\hline & & $1-2$ & 0.60 \\
\hline & & $3-5$ & 0.50 \\
\hline & & $6-8$ & 0.50 \\
\hline \multirow[t]{9}{*}{ absence } & contoured & $9-12$ & 0.60 \\
\hline & & $13-16$ & 0.70 \\
\hline & & $17-20$ & 0.80 \\
\hline & & $21-25$ & 0.90 \\
\hline & straight row & - & 1.00 \\
\hline & - & 0 & 0.60 \\
\hline & & $1-2$ & 0.45 \\
\hline & & $3-5$ & 0.38 \\
\hline & & $6-8$ & 0.38 \\
\hline \multirow[t]{5}{*}{ presence } & contoured & $9-12$ & 0.45 \\
\hline & & $13-16$ & 0.53 \\
\hline & & $17-20$ & 0.60 \\
\hline & & $21-25$ & 0.68 \\
\hline & straight row & - & 0.75 \\
\hline
\end{tabular}


should follow the contour or align transverse to the direction of the slope, because this will reduce the power of water flowing down the hill slope. Combining tillage on the contour with alternating strips of grass provides even further soil protection (e.g., Dillaha et al., 1989; Muscutt et al., 1993).

\subsection{The module "Crop"}

The indicator module "Crop" reflects the potentials of waste waters to reach cultivated crops and to have negative effects on their growth and development. Its value depends on one input variable only, i.e. vulnerability factor. This accounts for a number of different factors (application time in relation to seeding date, crop, stage of development), summarized in a coefficient ranging between 0 (the highest vulnerability) and 1 (the lowest vulnerability), as in Table 6. Suggested data derive from either author's experience or interpretation of results from Italian researches.

\subsection{The module "Soil"}

The indicator module "Soil" reflects site's suitability to take delivery of waste waters. Its value depends on seven input variables (Table 7): 1) macroporosity (resistance), 2) salinity (resistance), 3) pH (resistance), 4) exchangeable sodium percentage (resistance), 5) mean temperature in the month of shedding (protection), 6) field distance from drinking water sources (vulnerability), and 7) field distance from houses (vulnerability).

Soils with high values of macroporosity are desirable because better aerated. Higher values of both salinity and exchangeable sodium percentage imply ever-increasing risks to the environment, and are assumed to be the most in-
Table 6. Vulnerability factor of the module "Crop".

\begin{tabular}{lc}
\hline Land use & $\begin{array}{c}\text { Vulnerability } \\
\text { factor }(-)\end{array}$ \\
\hline \multicolumn{2}{c}{ Fallow period } \\
\hline fallow, 2 months before sowing \\
fallow, 1.5 months before sowing \\
fallow, 1 months before sowing \\
fallow, 0.5 months before sowing \\
fallow, < 0.5 months before sowing & 0.00 \\
Growing season & 0.50 \\
winter cereals, tillering & 0.25 \\
rapeseed, rosette & 0.00 \\
maize, 2-3 leaves & 0.70 \\
sunflower, 2-3 leaves & 0.70 \\
sugarbeet & 0.60 \\
potato, full canopy & 0.50 \\
leguminoseae grass, regrowth & 0.10 \\
gramineae grass, regrowth & 0.40 \\
pasture, re-growth & 0.30 \\
uncovered set-aside & 0.30 \\
olive, dormancy & 0.30 \\
wine grape, dormancy & 0.40 \\
fruit trees, dormancy & 0.90 \\
\hline
\end{tabular}

fluential module inputs (expert weights equal to 6 for both). Basic soils have to be preferred, to compensate for quite high acidity conveyed by waste waters. It is also desirable to shed waste waters when air temperature is rather high, as the higher is the temperature the faster is the waste water degradation. Unsuitable soils are those located near to either drinking water sources or houses. The $\mathrm{U}$ limits for both these inputs are set by Italian law (law 574/96, article 5).

\subsection{Aggregation of the modules}

The five modules described above can be used to compare alternative waste waters application options with respect to their potential environmental impact. The available options might be

Table 7. The indicator module "Soil": input variables, favorable (F) and unfavorable limits (U), expert weights. For details, see the text.

\begin{tabular}{|c|c|c|c|c|}
\hline \multicolumn{5}{|c|}{ Module "Soil" } \\
\hline \multirow[t]{2}{*}{ Type of factor } & \multirow[t]{2}{*}{ Input variable } & \multicolumn{2}{|c|}{ Limits } & \multirow[t]{2}{*}{ Expert weight } \\
\hline & & $\mathrm{F}$ & $\mathrm{U}$ & \\
\hline resistance & macroposority (\%) & 35 & 15 & 1 \\
\hline resistance & salinity $\left(\mathrm{EC}, \mathrm{mS} \mathrm{cm}^{-1}\right)$ & 2 & 4 & 6 \\
\hline resistance & $\mathrm{pH}(-)$ & 7.3 & 5.9 & 2 \\
\hline resistance & exchangeable sodium percentage (ESP, \%) & 5 & 15 & 6 \\
\hline protection & mean temperature in the month of shedding $\left({ }^{\circ} \mathrm{C}\right)$ & 25 & 5 & 1 \\
\hline vulnerability & field distance from drinking water sources (m) & 700 & 300 & 2 \\
\hline vulnerability & field distance from houses $(\mathrm{m})$ & 500 & 200 & 2 \\
\hline
\end{tabular}


ranked, for instance, by means of a multicriteria analysis technique, using the modules as evaluation criteria (Girardin et al., 2000). An alternative approach would be to aggregate the five modules (second-level aggregation) in some way into an overall indicator (i.e., ICARO), reflecting a global judgment about the impact of waste waters on the environment, again on a 0 to 1 scale. This can be done by summation, multiplication or a combination of both, according to aggregation schemes. For example: ICARO = (Waste waters + Soil $) \cdot($ Groundwater + Surface water + Crop $)$, or ICARO $=($ Waste waters + Soil $) \cdot \max$ (Groundwater, Surface water, Crop), etc.

We advocate here another mode of aggregation of the five modules, which uses decision rules, similar to that described above for the aggregation of input variables into the modules. The value of the indicator ICARO depends on the modules "Waste waters", "Groundwater", "Surface water", "Crop" and "Soil", according to a set of $2^{5}=32$ decision rules (not shown), derived from expert weights assigned (see later). The definition of the limits of the transition interval is the same for the five input modules: we assigned complete membership to $F$ if the value of the module is 0 (i.e., optimal waste water amount/quality, no risk to either groundwater, surface water, or crop, optimal soil properties and position) and complete membership to $\mathrm{U}$ if the value of the module is 1 .

In setting up the other decision rules we had to establish the relative importance of each module. In most indicators of environmental impact surface water is given much emphasis (e.g., van der Werf, 1996). Considering this, we decided to give the largest weight to the module "Surface water" (i.e., 30) in the aggregation of the modules. Based on our experience, decreasing importance was given to the other modules. As the amount of waste waters applied to soil is directly related to the impact on the envi-

Table 8. Relative incidence of each input variable on the value of the indicator, based on normalized weights.

\begin{tabular}{|c|c|}
\hline Input variable & Relative incidence on ICARO \\
\hline $\begin{array}{l}\text { Module "Waste water" } \\
\text { rate of application } \\
\text { time past from the last shedding } \\
\text { floating impurities } \\
\text { pH } \\
\text { SAR } \\
\text { electric conductivity }\end{array}$ & $\begin{array}{l}0.45 \times 0.25=0.1136 \\
0.27 \times 0.25=0.0682 \\
0.05 \times 0.25=0.0114 \\
0.05 \times 0.25=0.0114 \\
0.09 \times 0.25=0.0227 \\
0.09 \times 0.25=0.0227\end{array}$ \\
\hline $\begin{array}{l}\text { Module "Groundwater" } \\
\text { soil saturation rate } \\
\text { saturation conductivity } \\
\text { field distance from wells }\end{array}$ & $\begin{array}{l}0.40 \times 0.15=0.0600 \\
0.53 \times 0.15=0.0800 \\
0.07 \times 0.15=0.0100\end{array}$ \\
\hline $\begin{array}{l}\text { Module "Surface water" } \\
\text { rainfall erosivity } \\
\text { soil morphologic factor } \\
\text { soil erodibility } \\
\text { cover factor } \\
\text { field distance from water bodies } \\
\text { conservation management }\end{array}$ & $\begin{array}{l}0.13 \times 0.30=0.0333 \\
0.13 \times 0.30=0.0333 \\
0.13 \times 0.30=0.0333 \\
0.27 \times 0.30=0.0667 \\
0.13 \times 0.30=0.0333 \\
0.20 \times 0.30=0.0500\end{array}$ \\
\hline $\begin{array}{l}\text { Module "Crop" } \\
\text { vulnerability factor }\end{array}$ & $1.00 \times 0.10=0.1000$ \\
\hline $\begin{array}{l}\text { Module "Soil" } \\
\text { macroporosity } \\
\text { salinity } \\
\mathrm{pH} \\
\text { exchangeable sodium percentage } \\
\text { mean temperature in the month of shedding } \\
\text { field distance from drinking water sources } \\
\text { field distance from houses }\end{array}$ & $\begin{array}{l}0.05 \times 0.20=0.0100 \\
0.30 \times 0.20=0.0600 \\
0.10 \times 0.20=0.0200 \\
0.30 \times 0.20=0.0600 \\
0.05 \times 0.20=0.0100 \\
0.10 \times 0.20=0.0200 \\
0.10 \times 0.20=0.0200\end{array}$ \\
\hline
\end{tabular}



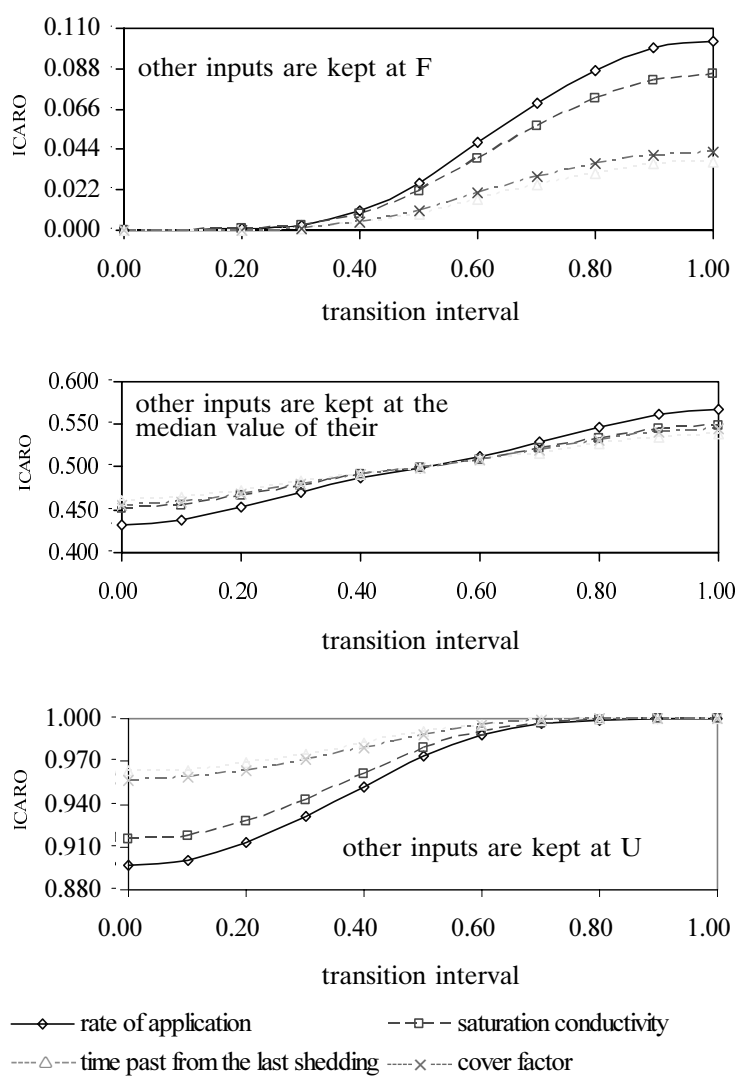

Figure 2. Sensitivity analysis of ICARO to variation of four input variables. Each input variable is varied over its transition interval from 0.0 (completely favorable) to 1.0 (completely unfavorable) while the other input variables are kept af Favorable (top graph), at the median value of their transition interval (middle graph) or at Unfavorable (bottom graph).

ronment, the module "Waste water" was considered of relatively high importance (i.e., expert weight equal to 25). Then, soil properties/position (module "Soil") have an effective role in influencing the mechanisms allowing the transfer and spread of waste waters to the sensitive targets (i.e., expert weight equal to 20). Groundwater is taken into higher consideration than crop in the assessment of environmental impact, thus larger weight was assigned to the module "Groundwater" (i.e., 15) than to the module "Crop" (i.e., 10).

The relative incidence of each input variable on the indicator, based on the weights only, can be deduced by combining the normalized weights of the input variables into their own module with the ones of the modules into the indicator (Table 8). In practice, the effective in- cidence of an input variable on the final score is dependent on either the value assumed by the variable itself, the values of the other inputs, and $\mathrm{F}$ and $\mathrm{U}$ limits attributed.

\subsection{Sensitivity analysis to input variables}

In order to illustrate the functioning of the system, we present the sensitivity showed by the indicator to variation of the four most influential input variables, i.e., rate of application, saturation conductivity, time past from the last shedding, cover factor (Table 8). Each input variable was varied over its transition interval, while the others were kept fixed either at the extremes of the transition interval, i.e. at F (Figure 2, top) and U (Figure 2, bottom), or at the median value (Figure 2, middle). The sensitivity analysis reflects the functioning of the system and provides some indication about the importance of each input variable on the value of ICARO. However, one should be aware that the effect of the variation of a particular input over its transition interval on the value of ICARO is dependent on the value of the other inputs. Therefore, results presented here should not be considered other than illustrations of the functioning of the system.

The four selected variables are not very influential when all other inputs are $\mathrm{F}$ (Figure 2, top) or U (Figure 2, bottom). In both these cases ICARO varies within a narrow range, from a maximum range of about 0.103 for rate of application (from 0 to $\sim 0.103$ when the others are F; from $\sim 0.897$ to 1 when the others are U), to a minimum of about 0.037 for time past from the last shedding (from 0 to $\sim 0.037$ when the others are F; from $~ 0.963$ to 1 when the others are $\mathrm{U})$. This means that ICARO is mostly influenced by the other inputs (taken together) under these conditions. More important is the influence of the selected variables on ICARO when all other inputs are kept at the middle value of their transition interval (Figure 2, middle). Under this condition, ICARO fluctuates between $\sim 0.432$ and $\sim 0.568$ over the range of rate of application, and between $\sim 0.461$ and $~ 0.539$ over the range of time past from the last shedding.

\subsection{The ICARO Software}

A MS Visual Basic program implements the expert system illustrated above. The inputs are entered by a friendly interface (in Italian only in 
the current version), structured in seven tabs: five tabs are relative to inputs and compute the modules, one tab is designed to compute the indicator, one tab is compiled with general data and shows the conditions imposed by the Italian law. Input data can be saved in ASCII files. A sample of files is included in the installation package. Utilities are also included allowing users to easily process a large amount of data (batch analysis), and explore the relative incidence of the input variables on the indicator score (sensitivity analysis).

A database of weather inputs which are relevant for the calculations is incorporated in the software, but only limited to locations of the province of Pisa in the current version.

The program is fully documented in the user's manual (Italian version only available in the current version), which gives detailed description of both the techniques being implemented and the underpinning science. The manual is provided with the software package and is available both on-line from the interface, and as a standalone help.

The software ICARO may be supplied to interested users on request. Use for non-commercial purposes is only allowed. The authors require that in any publication arising from use for research purposes the source of the program should be properly acknowledged. The authors also appreciate to receive a copy of the publication. A dedicated web site is under development (http://www.agr.unipi.it/daga/icaro/ICARO.htm). The help file is currently available for downloading (http://www.sipeaa.it/tools/icaro/icaro.htm).

Some software features follow, illustrating how the program deals with computational issues associated to module and indicator calculations.

\subsection{Module "Waste water"}

The user may select the proper option from two alternative oil extraction methods: traditional (mechanical pressure), centrifugation. This determines the $\mathrm{U}$ limit for the rate of application (see Table 1).

\subsection{Module "Groundwater"}

The user may want to compute soil saturation rate $\left(\mathrm{V}_{\mathrm{s}}, \mathrm{d}^{-1}\right)$, based on two alternative equations:

- field capacity $(\mathrm{FC}): \mathrm{V}_{\mathrm{s}}=(\mathrm{p} / \mathrm{n}) \cdot \mathrm{FC} \cdot \mathrm{H}$

- bulk density (BD): $\mathrm{V}_{\mathrm{s}}=(\mathrm{p} / \mathrm{n}) \cdot[(2.65-\mathrm{BD}) /$ 2.65)] $\mathrm{z} \cdot \mathrm{H}$ where $\mathrm{p}$ is rainfall in the month when waste waters are shed in the field $\left(\mathrm{mm}\right.$ month $\left.^{-1}\right), \mathrm{n}$ is the number of rainy day in that month (days month $^{-1}$ ), $\mathrm{H}$ is tillage depth $(\mathrm{mm})$.

If not available, values for $\mathrm{FC}\left(\mathrm{mm} \mathrm{mm}^{-1}\right)$ and BD $\left(\mathrm{t} \mathrm{m}^{-3}\right)$ can be estimated from texture via pedotransfer functions (Saxton et al., 1986). A pedotransfer function by Campbell and Shiozawa (1992) is also implemented to estimate the saturated hydraulic conductivity $\left(\mathrm{K}_{\mathrm{s}}, \mathrm{mm} \mathrm{h}^{-1}\right)$ from texture.

\subsection{Module "Surface water"}

Energy factors, i.e. rainfall erosivity ( $\mathrm{R}, \mathrm{MJ} \mathrm{mm}$ $\mathrm{ha}^{-1} \mathrm{~h}^{-1} \mathrm{yr}^{-1}$ ) and morphologic factor (SL), can be calculated according to simplified forms of the USLE approach (Wischmeier and Smith, 1978; Arnoldus, 1980):

$$
\begin{gathered}
\mathrm{R}=\left[4.17 \cdot \Sigma\left(\mathrm{p}^{2} / \mathrm{P}\right)-152\right] \cdot 17.02 \\
\mathrm{SL}=(\mathrm{a} / 22.13)^{\mathrm{b}} \cdot\left(0.065+0.045 \cdot \mathrm{i}+0.0065 \cdot \mathrm{i}^{2}\right)
\end{gathered}
$$

where $\mathrm{p}$ is rainfall in the month when waste waters are shed in the field $\left(\mathrm{mm} \mathrm{month}^{-1}\right), \mathrm{P}$ is average yearly rainfall $\left(\mathrm{mm}\right.$ year $\left.{ }^{-1}\right)$, a is the slope length $(\mathrm{m}), \mathrm{i}$ is the slope $(\%)$, and $\mathrm{b}$ is a dimensionless factor depending on the slope $(0.5$ if $\mathrm{i}$ $>5 \%, 0.4$ if $3 \%<\mathrm{i} \leq 5 \%, 0.3$ if $1<\mathrm{i} \leq 3 \%, 0.2$ if $\mathrm{i} \leq 1 \%$ ).

The computation of soil erodibility $(\mathrm{K}, \mathrm{t} \mathrm{h}$ $\mathrm{MJ}^{-1} \mathrm{~mm}^{-1}$ ) is also based on USLE (Wischmeier and Smith, 1978):

$$
\begin{gathered}
\mathrm{K}=\left[2.1 \cdot \mathrm{TF}^{1.14} \cdot 10^{-4} \cdot(12-\mathrm{OM})+3.25\right. \\
\quad(\mathrm{SF}-2)+2.5 \cdot(\mathrm{PF}-3)] \cdot 0.1317 / 100
\end{gathered}
$$

where $\mathrm{TF}$ is texture factor $-\mathrm{TF}=(\%$ silt $+\%$ very fine sand).(100-\%argilla) -, OM is soil organic matter $(\%), \mathrm{SF}$ is structure factor (ranging from 1 for very fine granular structure to 4 for polyedric structure), $\mathrm{PF}$ is permeability factor (ranging from 1 for $K_{s}>127$ to 6 for $K_{s}<1$ ).

Both cover factor and conservation management cannot be entered directly. They are selected from a list of options, as in Table 4 and Table 5, respectively.

\subsection{Module "Crop"}

The value for vulnerability factor cannot be entered directly. It can only be selected from a list of options (Table 6).

\subsection{Module "Soil"}

The mean air temperature for the month when waste waters are applied in a field can be en- 
tered directly or selected from the database including historical weather data for the location of interest (the database is limited to the province of Pisa only in the current version). The macroporosity (MP, \%) can be either entered in the relative domain or estimated, based on its relation to field capacity $\left(\mathrm{FC}, \mathrm{mm} \mathrm{mm}^{-1}\right.$ ) and $\mathrm{BD}\left(\mathrm{t} \mathrm{m}^{-3}\right)$ :

$$
\mathrm{MP}=[(2.65-\mathrm{BD}) / 2.65-\mathrm{CC}] \cdot 100
$$

As already mentioned above, both FC and $\mathrm{BD}$ may be estimated by texture data.

\subsection{Indicator}

The indicator can either be computed in its complete form by aggregating five modules, or in a partial form by aggregating 2,3 , or 4 modules. Although partial, the last option is allowed to permit a conclusion on the environmental impact associated to waste water's shedding when some inputs are missing.

\section{Discussion}

In the design of a system to assess waste waters environmental impact two major questions have to be answered: a) which input variables should be taken into account, and b) how should the input variables be aggregated. The method presented in this paper proposes an answer to both questions, but its relevance lies primarily in the answer it provides to the second question. Compared to other methods, this approach contains two key elements: the use of a fuzzy set and the use of decision rules. The use of a fuzzy set provides a well-designed solution to the problem of deciding the cut-off values for input variables: e.g., the limit between $\mathrm{F}$ response, $\mathrm{U}$ response, and transition response. The use of decision rules provides a "rational" aggregation of input variables in the related module: e.g., soil saturation rate, saturation conductivity and field distance from wells in the module "Groundwater". The combination of these two concepts (limits in the response, mode of aggregation) in sets of fuzzy rules is attractive because, although the combinations of values of input variables are potentially infinite, a single set of fuzzy rules connects them all.

In this application, the system is based on a compromise between operational suitability (the assessment of the environmental impact) and flexibility (hierarchization of objectives and aggregation of preferences). It requires extended corroboration, considering that the objective of an expert system is the simulation of a human expert. The expert system is corroborated if it displays, under a variety of conditions, the same responses that a human expert would display. Experts are therefore invited to comment on the set-up and results of this system. If there is disagreement between expert perception of environmental impact and the inputs of the system, the cause of this divergence will be examined in view of: a) choice of input variables; b) choice of the limits of the transition interval; c) formulation of the decision rules; and d) formulation of the mode of aggregation of the modules. All of these points may be modified according to expert consensus, after an extensive testing of the methodology. The software ICARO may help to test the indicator on a variety of conditions. Allowing the creation of reusable modules and indicators (ASCII files), ICARO may serve as a convenient means to support collaborative work among large, distributed network of either scientists or end-users involved in the assessment of the environmental impact associated to waste water's shedding.

\section{Conclusions}

We propose a fuzzy expert system reflecting our expert judgment of potential waste water environmental impact. Providing usable values of input variables, the method allowed to build an aggregated indicator with a modular structure. The system takes into account three types of input variables: waste water properties, site-specific conditions, waste water toxicity to crops. The resulting output can be used as a support to rank or choose among alternative waste water application options.

Although a wide expert examination is still required for a general consensus about weights and limits applied to both input variables and aggregated modules, the fuzzy sets suggested here may represent a pragmatic approach towards a satisfactory solution.

This approach to the evaluation of potential waste water environmental impact is useful for a number of reasons: 
- it allows interested parties to express mathematically individual or collective values and preferences (uncertainty factors);

- it highlights the degree of waste water's shedding acceptance/rejection associated with each information source (e.g., waste water amount and composition, site-specific conditions, phytotoxicity);

- it allows comparing alternative options;

- it facilitates structuring of various components of the evaluation process;

- it reduces several sources and levels of information into a single value;

- it allows examination of operational equivalence between several input variables and modules.

The modular structure also presents advantages. In the first place, interested parties have access to both a synthetic indicator reflecting overall judgment and to each of the modules. This means a transparency of each step, and a control opportunity exists for anybody concerned by the process itself. Secondly, the mode of aggregation of modules can be changed and new modules can be eventually added. The multi-value nature of the issue we are dealing with is explicitly stated, the rules are easy to read, and the numerical scores used for their conclusion are easy to tune to match expert opinions. The method illustrated here is flexible and can be easily modified to aggregating other variables. Moreover, the same method could be conveniently applied to assess the potential environmental impact associated to pollutants other than waste waters from olive oil extraction, which might be shed in cultivated fields, e.g. industrial waters.

ICARO provides an evaluation tool by which various people (scientists, decision-makers, farmers), with different standpoints, can discuss around a common problem (how evaluate the environmental impact of waste water's shedding in cultivated fields), following a transparent and non-ambiguous methodology. The evaluation of the expert system is an ongoing project. Most of the experts involved in its development supplied valuable remarks. Several modifications and additions were made, leading to the version presented here. At operational level, certain precautions can be taken to prevent interested parties from shedding highly impacting waste waters. Of course, the lower the value of the indicator the better the chance to shed waste waters in a field without impacting on the environment. The experience accumulated so far suggested us that ICARO values can be categorized in low (0-0.33), intermediate (0.33-0.66), and high (0.66-1.00) scores. The environmental risk is high when high values of ICARO occur, thus the shedding should not be authorized, unless consistent modifications in the shedding strategy are done (i.e., lessening of the rate of application, change of the site, etc.) or carrying out supplementary surveys. Intermediate values of the indicator make possible the distribution, but suggest little modifications in the shedding strategy, essentially the timing of execution or the cropping system choice. No modification in the strategy is required when ICARO falls within the range of low values. These guidelines will be corroborated by further testing. ICARO is about being tested on a number of fields, starting from the province of Pisa, involving farmers and public decision-makers. The improvement and evaluation of ICARO is thus carried out in interaction with the interested parties.

\section{Acknowledgements}

The authors would like to thank Donata Accogli, Lucia Ceccarini, Laura Ercoli, Claudia Giannini, Alessandro Masoni, Tiziana Sabbatini, Marj Tonini, Cristiano Tozzini for providing valuable contributions on the setup of the indicator. This research is under the auspices of the Italian National Research Council (CNR) and the Italian Ministry of Education, University and Scientific Research (former MURST, presently MIUR), project "Riciclo dei reflui del sistema agricolo-industriale. Linea Reflui Oleari" (web page at: HTTP://USERS.UNI-MI.IT/ $\sim$ fsangio/cnr/olio1.htm).

\section{References}

Arnoldus H.M.J. 1980. An approximation of the rainfall factor in the universal soil loss equation. In: De Boodt M., Gabriels D. (eds.): Assessment of erosion, 127132. John Wiley and Sons, New York.

Bacci L., Conese C., Maselli F., Romani M., Zienna P. 1989. Metodologia per la costruzione di mappe di rischio ambientale: un'applicazione per la Val di Cornia. I.A.T.A.-C.N.R., Florence.

Bardossy A., Bogardi I., Duckstein L. 1985. Composite programming as an extension of compromise programming. In: Serfini P. (ed.): Mathematics of multiple objective optimisation, 375-408. Springer-Verlag, Wien. 
Bellocchi G., Acutis M., Fila G., Donatelli M. 2002. An indicator of solar radiation model performance based on a fuzzy expert system. Agron. J., 94:1222-1233.

Benitez F.J., Beltran-Heredia J., Acero J., Pinilla M. 1997. Simultaneous photodegradation and ozonation plus UV radiation of phenolic acids-Major pollutants in agro-industrial waste waters. J. Chem. Technol. and Biotechnol., 70:253-260.

Bonari E., Ceccarini L. 1991. Spargimento delle acque di vegetazione dei frantoi sul terreno agrario. L'Informatore Agrario, 13:49-57.

Bonari E., Ceccarini L. 1993. Sugli effetti dello spargimento delle acque di vegetazione sul terreno agrario: risultati di una ricerca sperimentale. Genio Rurale, 5:60-67.

Bonari E., Ceccarini L. 2001. Effetti dei reflui oleari sulla produzione di alcune colture agrarie. In: I sottoprodotti dei frantoi oleari, 3, 121-146. Progetto editoriale PANDA Edizioni L'Informatore Agrario, Verona.

Bonari E., Giannini C., Ceccarini L., Silvestri N., Tonini M., Sabbatici T. 2001. Spargimento delle acque di vegetazione dei frantoi oleari su terreno agrario. L'Informatore Agrario, suppl. 50:8-12.

Bonari E., Silvestri N. 2003. Acque di vegetazione dei frantoi oleari. In: AA.VV. (eds.): Linee guida per il riutilizzo sul suolo di acque reflue depurate e per l'utilizzazione agronomica delle acque di vegetazione e delle acque reflue di aziende agro-alimentari. ANPA (Agenzia Nazionale per la Protezione dell'Ambiente). IGER srl, Roma. (in press).

Borja R., Martin A, Alba J., Fiestas J.A. 1992. Enhancement of the anaerobic digestion of olive mill wastewater by the removal of phenolic inhibitors. Process Biochem., 27:231-237.

Bouchon-Meunier B. 1993. La logique floue. Presses Universitaires de France, Paris, France.

Campbell G.S., Shiozawa S. 1992. Prediction of hydraulic properties of soils using particle-size distribution and bulk density data. In: Van Genuchten M.Th., Leij F.J., Lund L.J. (eds.): Proceedings of the International Workshop of "Indirect methods of measuring soil hydraulic properties”, 11-13 October. Riverside, CA, USA, 317-328.

Ciafardini G., Zullo B.A., Cioccia G. 1998. Effetti delle acque reflue dei frantoi su due batteri azotofissatori. L'Informatore Agrario, 15:35-37.

Cornelissen A.M.G., van den Berg J., Koops W.J., Grossman M., Udo H.M.J. 2001. Assessment of the contribution of sustainability indicators to sustainable development: a novel approach using fuzzy set theory. Agr. Ecosyst. Environ., 86:173-185.

Coombs J., Hall K. 2000. N-F 2000 - AIR programme final project results disseminated under FAIR-CT961904. CPL Press, Newbury.

De Simone C., Raglione M., De Marco A., D'Ambrosio C. 1998. Analisi degli effetti genotossici delle acque di vegetazione di frantoi oleari. Agricoltura Ricerca, 173:75-80.

Di Giovacchino L. 2001. I sottoprodotti della lavorazione delle olive. Caratteristiche qualitative e quantitative. In: I sottoprodotti dei frantoi oleari, 3, 29-40. Progetto editoriale PANDA Edizioni L'Informatore Agrario, Verona.

Dillaha T.A., Reneau R.B., Mostaghimi S., Lee D. 1989. Vegetative filter strips for agricultural non-point source pollution control. Trans. of ASAE, 32:513-519.

Dubois D., Prade H. 1980. Fuzzy sets and systems: theory and applications. Academic Press, New York.

Fiorentini R., Andrich G., Loni A., Pacciardi A., Galoppini C. 1985 . Le acque reflue dei frantoi. Composizione e tecnologia di smaltimento. Giornata di qualificazione dell'assistenza tecnica in agricoltura. Braccagni, Grosseto.

Girardin P., Bockstaller C., van der Werf H.M.G. 2000. Assessment of potential impact of agricultural practices on the environment - the AGRO*ECO Method. Environ. Impact Assess. Rev., 20:227-239.

Goyal S.K., Deshpande V.A. 2001. Comparison of weight assignment procedures in evaluation of environmental impacts. Environ. Impact Assess. Rev., 21:553-563.

Hall L.O., Kandel A. 1991. The evolution from expert systems to fuzzy expert systems. In: Kandel A. (ed.): Fuzzy expert systems theory, 3-21. CRC Press, Boca Raton.

James D.W., Hanks R.J., Jurinak J.H. 1982. Modern irrigated soils. John Wiley and Sons, New York.

Keeney R.L., Raiffa H. 1993. Decisions with multiple objectives: preferences and value tradeoffs. Cambridge University Press, New York.

Kuncheva L.I., Wrench J., Jain L.C., Al-Zaidan A.S. 2000. A fuzzy model of heavy metal loadings in Liverpool bay. Environ. Modell. Softw., 15:161-167.

Matzavinos D., Hellenbrand R., Metcalf I.S., Livingston A.G. 1996. Partial wet oxidation of p-coumaric acid: Partial oxidation intermediates, reaction pathways and implications for waste water treatment. Wat. Res., 30:2969-2976.

Muscutt A.D., Harris G.L., Bailey S.W., Davies D.B. 1993. Buffer zones to improve water quality: a review of their potential use in UK agriculture. Agr. Ecosyst. Environ., 45:59-77.

Odhiambo L.O., Yoder R.E., Yoder D.C. 2001. Estimation of reference crop evapotranspiration using fuzzy state models. Trans. of ASAE, 44:543-550.

Pacifico A. 1989. Dossier acque di vegetazione. Agricoltura ed Innovazione, notiziario dell'Enea e di Renagri, 11,38 .

Potenz D., Righetti E., Pellettieri A., Girardi F., Antonacci P., Calianno L.A., Pergolese G. 1985. Evoluzione della fitotossicità in un terreno trattato con acque reflue di frantoi oleari. Inquinamento, 5:49-55.

Poulios I., Makri D., Prohaska X. 1999. Photocatalytic 
treatment of olive milling waste water: oxidation of photocatechuic acid. Global Nest the Int. J., 1:55-62.

Rana G., Rinaldi M., Introna M. 2003. Volatilisation of substances after spreading olive oil waste water on the soil in a Mediterranean environment. Agr. Ecosyst. Environ., 96:49-58.

Roussel O., Cavelier A., van der Werf H.M.G. 2000. Adaptation and use of fuzzy expert system to assess the environmental effect of pesticides applied to field crops. Agric., Ecosyst. Environ., 80:143-148.

Saxton K.E., Rawls W.J., Romberger J.S., Papendick R.I. 1986. Estimating generalized soil-water characteristics from texture. Soil Sci. Soc. Amer. J., 50:10311036.

Silvestri N., Fila G., Bellocchi G., Bonari E. 2003. ICARO: un software per valutare l'idoneità dei terreni agrari alla distribuzione delle acque reflue dei frantoi oleari. Atti del XXXV Convegno della Società Italiana di Agronomia, 16-18 September, Portici (NA), Italy, 281-282.

Soil Survey Staff, Natural Resource Conservation Service 1993. Soil survey manual. United States De- partment of Agriculture, Handbook No. 18, Government Printing Office. Washington D.C.

Sugeno M. 1985. An introductory survey of fuzzy control. Information Sciences, 36:59-83.

Tomati U. 2001. Impatto ambientale ed uso di compost dalle acque reflue di frantoio. In: Tedeschi P., D'Andria R., Touzani A. (eds.): Atti del convegno "Gestione dell'acqua e del territorio per un'olivicoltura sostenibile", 24-28 September, Naples, Italy, 296-311.

Van der Werf H.M.G., Zimmer C. 1998. An indicator of pesticide environmental impact based on a fuzzy expert system. Chemosphere, 36:2225-2249.

Wischmeier W.H., Smith D.D. 1978. Predicting rainfall erosion losses. Agricultural Handbook 537. U.S. Department of Agriculture, Agricultural Research Service, Washington, DC.

Zadeh L.A. 1965. Fuzzy sets. Information and Control, 8:338-353.

Zouari N., Ellouz R. 1996. Toxic effect of coloured olive compounds on the anaerobic digestion of olive oil mill effluents in UASB-like reactors. J. Chem. Tech. Biotechnol., 66:414-420. 